\title{
On the electronic structure of methyl butyrate and methyl valerate $^{\star, \star \star}$
}

Małgorzata A. Śmiałek ${ }^{1, a}$, Denis Duflot ${ }^{2}$, Nykola C. Jones ${ }^{3}$, Søren Vrønning Hoffmann ${ }^{3}$, Lucia Zuin ${ }^{4}$, Michael Macdonald ${ }^{4}$, Nigel J. Mason ${ }^{5}$, and Paulo Limão-Vieira ${ }^{6}$

1 Department of Control and Power Engineering, Faculty of Ocean Engineering and Ship Technology, Gdańsk University of Technology, Gabriela Narutowicza 11/12, Gdańsk 80-233, Poland

2 Univ. Lille, CNRS, UMR 8523 - PhLAM - Physique des Lasers Atomes et Molcules, Lille 59000, France

3 ISA, Department of Physics and Astronomy, Aarhus University, Ny Munkegade, Building 1520, Aarhus C 8000, Denmark

4 Canadian Light Source Inc., 44 Innovation Boulevard, Saskatoon S7N 2V3, Canada

5 School of Physical Sciences, Ingram Building, University of Kent, Canterbury CT2 7NH, UK

6 Atomic and Molecular Collisions Laboratory, CEFITEC, Department of Physics, Universidade NOVA de Lisboa, Caparica 2829-516, Portugal

Received 29 February 2020 / Received in final form 14 April 2020

Published online 7 July 2020

(c) The Author(s) 2020. This article is published with open access at Springerlink.com

\begin{abstract}
We present novel results of the analysis of the electronic structure of two aliphatic esters: methyl butyrate and methyl valerate. High-resolution photoabsorption spectra were collected and analyzed over the energy range 4.0-10.8 eV and showed for both the molecules not only a clear band of the HOMO to LUMO transition, but also vibronic structure associated with the first Rydberg-valence transition. Photoelectron spectra recorded from 9 to over $28 \mathrm{eV}$ revealed many ionization states with the first adiabatic ionization energies found to be $9.977 \mathrm{eV}$ and $9.959 \mathrm{eV}$ for methyl butyrate and methyl valerate, respectively. Ab initio calculations have been performed in order to help assign the photoabsorption and photoelectron features. Photolysis life times in the atmosphere were calculated revealing that photolysis is not competitive over hydroxyl radical scavenging in the process of removal of these esters from the atmosphere.
\end{abstract}

\section{Introduction}

The knowledge of the electronic structure and properties of esters is of common interest in many disparate areas and therefore has been studied over many decades, however the data still needs to be updated either because they are outdated, were recorded with poor resolution, or are simply absent. Esters occur both naturally, being secreted from plants, and as a by-product of industrial processes. These compounds are widely used in the food and flavoring industry due to their distinct aroma $[1,2]$, but they also are of potential interest to astrochemists, who find the smallest members of this group in the interstellar medium, which is of interest for their possible role in the origins of life [3]. Both molecules of interest can serve as insecticides [4]. Methyl valerate in its pure form is used as plasticizer [5] and shows potential for use in the production of biofuels [6]. Due to their low vapour pressure that makes them easy to handle, both esters are produced on a massive scale and thus are likely to be released into

\footnotetext{
* Contribution to the Topical Issue "Atomic Cluster Collisions (2019)", edited by Alexey Verkhovtsev, Pablo de Vera, Nigel J. Mason, Andrey V. Solov'yov.

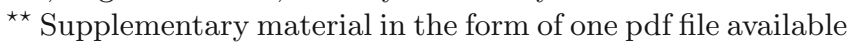
from the Journal web page at

https ://doi.org/10.1140/epjd/e2020-10125-5

a e-mail: smialek@pg.edu.pl
}

the atmosphere. Since it was shown that the main products of photolysis of such esters are carbon monoxide and dioxide, it is crucial to gain an insight into their structure, properties and photoabsorption cross sections [7].

Previously we have reported our findings on methyl formate [8], ethyl formate [9], isobutyl formate [10], ethyl acetate [11], isobutyl acetate [12] and some acetates and propionates [13]. Here we present our findings on a further two methyl esters: butyrate and valerate. The high-resolution VUV photoabsorption and photoelectron spectra presented here were measured for the first time for these compounds. The measured photoabsorption cross-sections have been used to calculate the photolysis lifetimes of these compounds in the upper atmosphere $(20-50 \mathrm{~km})$ of the Earth. The experimental findings are supported by theoretical calculations that allowed the determination of the ionization energies in the photoelectron spectra of both compounds and revealed predominantly mixed valence-Rydberg character of the transitions resolved in the photoabsorption spectra.

\section{Experimental}

\subsection{The samples}

The liquid samples used in both the VUV photoabsorption measurements (PA) and the photoelectron spectroscopy 


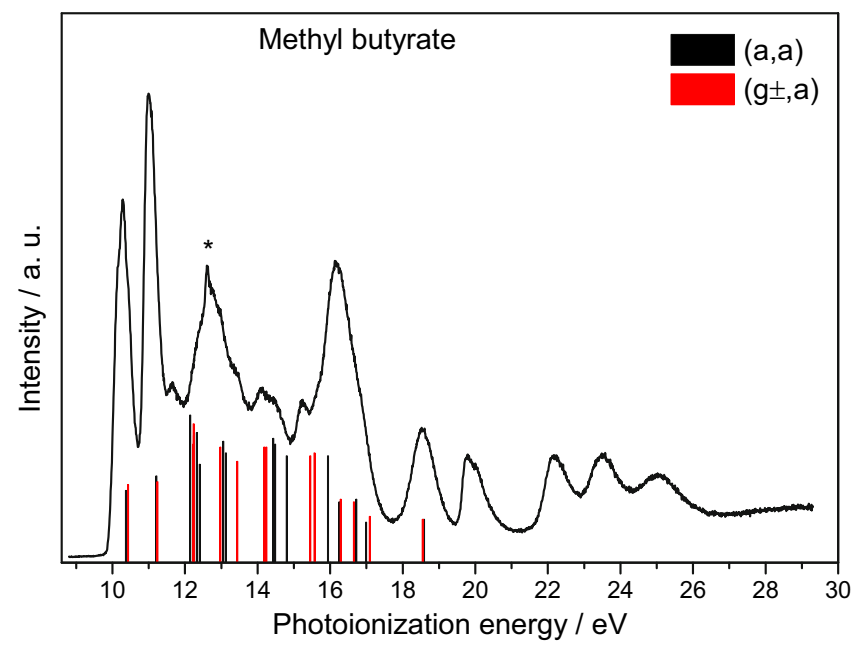

Fig. 1. Photoelectron spectrum of methyl butyrate, $\mathrm{C}_{5} \mathrm{H}_{10} \mathrm{O}_{2}$, in the $9.0-29.0 \mathrm{eV}$ region, collected at $80 \mathrm{eV}$ initial photon energy; ${ }^{*}$ denotes ${ }^{2} \mathrm{~B}_{1} \mathrm{H}_{2} \mathrm{O}$ contamination; the stick spectrum represents the computed ionization energies at the M06$2 \mathrm{X} /$ aug-cc-pVTZ geometry with the P3+ method for the most abundant conformers: $(a, a)$, black, and $(g \pm, a)$, red.

(PES) experiments were purchased from Sigma-Aldrich with a stated purity of $99 \%$. The samples were degassed by repeated freeze-pump-thaw cycles with no further purification.

\subsection{Photoelectron measurements}

The photoelectron spectra of methyl butyrate, Figure 1, and methyl valerate, Figure 2, were measured at the VLSPGM beamline [14] at the Canadian Light Source facility in Saskatoon, Canada, using a Double Toroidal Coincidence Spectrometer, that was designed and used for analysis of noble gases and small, diatomic molecules [15], but it has recently been demonstrated that it may also be used for measurements of more complex systems [16]. In our experiments we have used the data collected by the $180^{\circ}$ toroidal detector, set at a pass energy of $4 \mathrm{eV}$. The measured resolution from the nitrogen calibration spectra was $60 \mathrm{meV}$. The photoexcitation energy of the photoelectron spectrum presented here was $80 \mathrm{eV}$, recorded with the entrance and exit slits of the VLS-PGM beamline set at $50 \mu \mathrm{m}$.

Spectra presented here were calibrated against the $X^{2} \Sigma_{g}^{+}, \nu^{\prime}=0$ and $A^{2} \Pi_{u}, \nu^{\prime}=0$ peaks of $\mathrm{N}_{2}^{+}$, rounded to three decimal places $[17,18]$.

The stars marked on the spectra in the figures denote the ${ }^{2} \mathrm{~B}_{1}$ ionic state from some water contamination could also be used to check the accuracy of the calibration of the energy scale.

\subsection{Photoabsorption measurements}

The high-resolution VUV photoabsorption spectra of methyl butyrate, Figure 3, and methyl valerate, Figure 4, were measured at the UV1 beam line of the ASTRID synchrotron light source at Aarhus University, Denmark. The

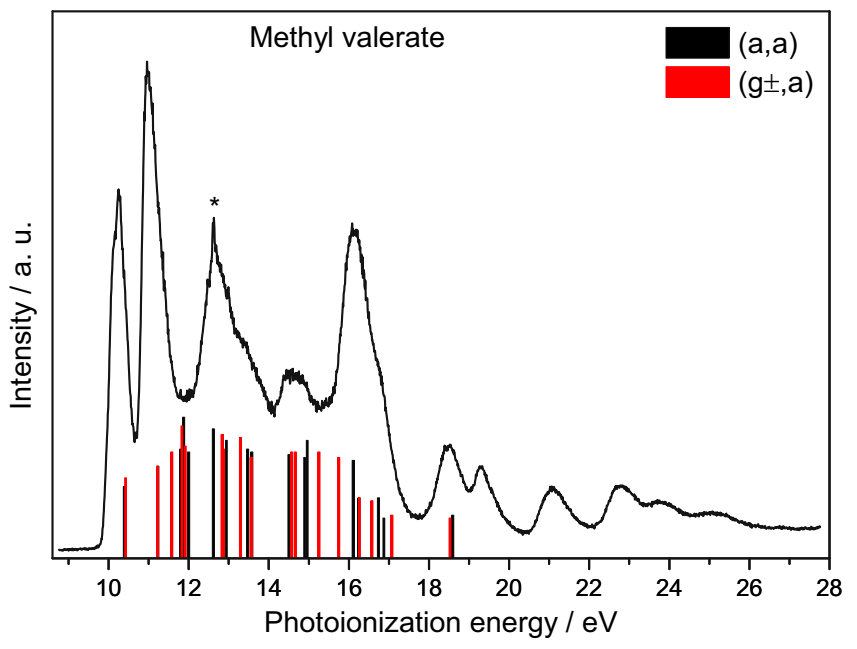

Fig. 2. Photoelectron spectrum of methyl valerate, $\mathrm{C}_{6} \mathrm{H}_{12} \mathrm{O}_{2}$, in the $9.0-28.0 \mathrm{eV}$ region, collected at $80 \mathrm{eV}$ initial photon energy; ${ }^{*}$ denotes ${ }^{2} \mathrm{~B}_{1} \mathrm{H}_{2} \mathrm{O}$ contamination; the stick spectrum represents the computed ionization energies at the M062X/aug-cc-pVTZ geometry with the P3+ method for the most abundant conformers: $(a, a)$, black, and $(g \pm, a)$, red.

experimental apparatus has been described in detail previously [19].

The sample pressure is measured using a capacitance manometer (Baratron). To ensure that the data were free of any saturation effects $[20,21]$, the cross sections were measured over the pressure range $0.07-1.27$ mbar with typical attenuations below $50 \%$. A background scan is recorded with the cell evacuated. Absolute photoabsorption cross sections are then obtained using the BeerLambert attenuation law

$$
I_{t}=I_{0} \times \exp (-n \sigma x),
$$

where $I_{t}$ is the radiation intensity transmitted through the gas sample, $I_{0}$ is that through the evacuated cell, $n$ is the molecular number density of the sample gas, $\sigma$ is the absolute photoabsorption cross section, and $x$ is the absorption path length $(15.5 \mathrm{~cm})$ [22]. A small amount of water contamination $(<15 \%)$ was observed in the spectra recorded for these samples. The water contribution was subtracted in the present spectra. Due to this, the accuracy of the cross-section is estimated to be around $\pm 15 \%$.

\section{Computational methods}

All the calculations have been performed using the Gaussian $16 \mathrm{rev}$ B.01 code [23]. The geometry of the conformers was optimised at the MP2 level, as well as with density functional theory (DFT), using the ultrafine grid size. As discussed in detail in the Supplementary Information (SI), several methods were tested on the relative energies of the conformers and compared with previous works $[24,25]$. The M06-2X [26] was thus employed. The optimized geometry of the conformers was obtained using the tight criteria and unscaled zeropoint vibrational energies were calculated within the 


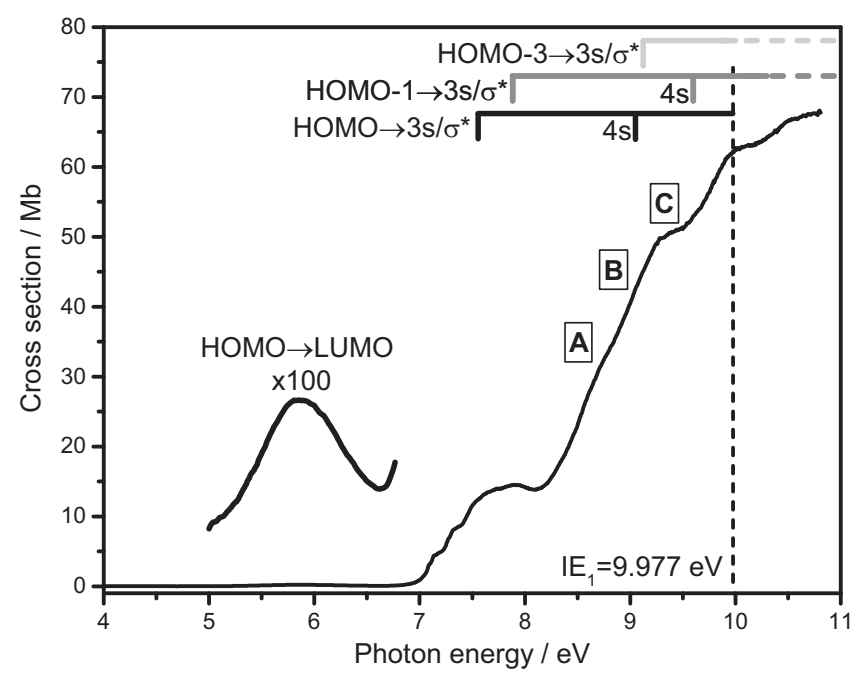

Fig. 3. Photoabsorption spectrum of methyl butyrate, $\mathrm{C}_{5} \mathrm{H}_{10} \mathrm{O}_{2}$, in the $4.0-10.8 \mathrm{eV}$ region; close-up shows the first valence $\mathrm{HOMO} \rightarrow \mathrm{LUMO}$ transition. See text for further details.

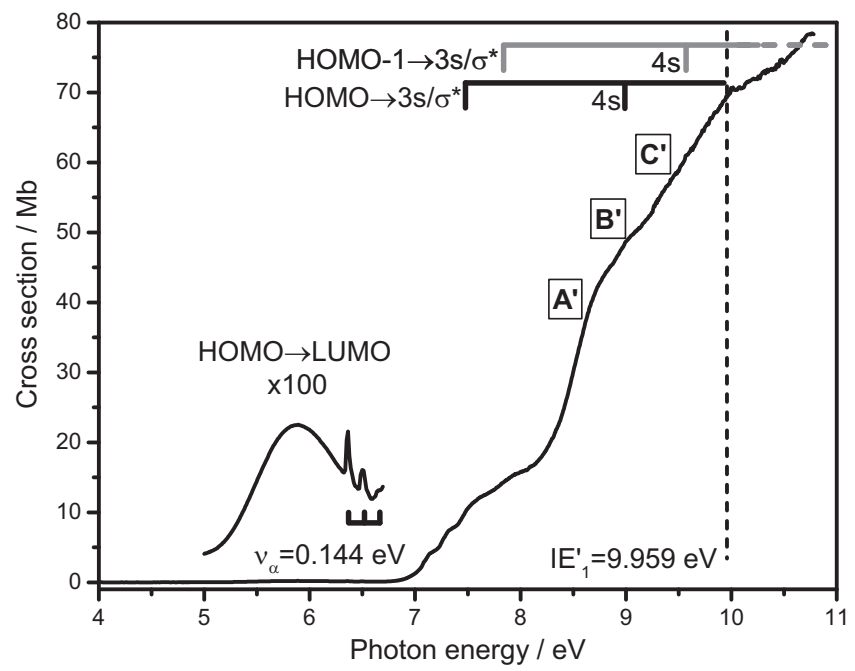

Fig. 4. Photoabsorption spectrum of methyl valerate, $\mathrm{C}_{6} \mathrm{H}_{12} \mathrm{O}_{2}$, in the $4.0-10.8 \mathrm{eV}$ region; close-up shows the first valence $\mathrm{HOMO} \rightarrow \mathrm{LUMO}$ transition. See text for further details.

harmonic approximation. The basis set used for these calculations is Dunning's aug-cc-pVTZ [27,28]. For the calculation of higher Rydberg states, this basis set was supplemented with a set of $(8 s 8 p 3 d)$ diffuse functions taken from Kaufmann et al. $[22,29]$ centred on the carbon atom close to the middle of the molecule. The oscillator strengths were evaluated with the length gauge. The assignment of the transitions was performed by visual inspection of the Natural Transition Orbitals (NTO's) [30] using the Chemcraft software [31]. Finally, the ionization energies were obtained at the OVGF, P3 and renormalized P3+ levels (see [32,33] for recent reviews). Detailed information on computational methods and structure on both molecules can be found in the SI.

\section{Structure of methyl butyrate and methyl valerate}

According to previous results, there are eight possible conformers for methyl valerate [24] and four for methyl butyrate [25]. Nonetheless, the analysis of the rovibrational spectroscopic data shows that for both of these esters, only the $(a, a)$, with $C_{S}$ symmetry, and $(g \pm, a)$, with no symmetry, conformers are present in almost the same quantities. Therefore, only these two conformers were investigated.

In Figures 5 and 6 the structures together with the highest occupied molecular orbital, HOMO, HOMO-1, HOMO-2 localization on both the conformers and LUMO for the $(a, a)$ one, are shown for methyl butyrate and methyl valerate. The bond lengths can be found in the SI. The orbitals in square brackets denote the core ones, the remaining are valence orbitals. For the $(a, a)$ conformer of methyl butyrate the electron configuration is $\left[1 a^{\prime 2} 2 a^{\prime 2}\right.$ $\left.3 a^{\prime 2} 4 a^{\prime 2} 5 a^{\prime 2} \quad 6 a^{\prime 2} \quad 7 a^{\prime 2}\right] 8 a^{\prime 2} 9 a^{\prime 2} 10 a^{\prime 2} 11 a^{\prime 2} 12 a^{\prime 2} 13 a^{\prime 2}$ $14 a^{\prime 2} 15 a^{\prime 2} \quad 1 a^{\prime \prime 2} 16 a^{\prime 2} 2 a^{\prime \prime 2} 17 a^{\prime 2} 18 a^{\prime 2} \quad 3 a^{\prime \prime 2} 19 a^{\prime 2} \quad 4 a^{\prime \prime 2}$ $20 a^{\prime 2} 21 a^{\prime 2} 4 a^{\prime \prime 2} 5 a^{\prime \prime 2} 22 a^{\prime 2}$, whereas for $(g \pm, a)$ one the

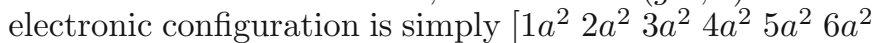
$\left.7 a^{2}\right] 8 a^{2} 9 a^{2} 10 a^{2} 11 a^{2} 12 a^{2} 13 a^{2} 14 a^{2} 15 a^{2} 16 a^{2} 17 a^{2} 18 a^{2}$ $19 a^{2} 20 a^{2} 21 a^{2} 22 a^{2} 23 a^{2} 24 a^{2} 25 a^{2} 26 a^{2} 27 a^{2} 28 a^{2}$.

Similarly, for methyl valerate the configuration of the

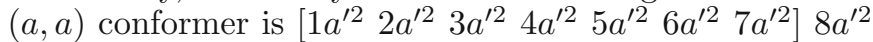
$9 a^{\prime 2} 10 a^{\prime 2} 11 a^{\prime 2} 12 a^{\prime 2} 13 a^{\prime 2} 14 a^{\prime 2} 15 a^{\prime 2} 16 a^{\prime 2} 17 a^{\prime 2} 1 a^{\prime \prime 2}$ $18 a^{\prime 2} \quad 2 a^{\prime \prime 2} 19 a^{\prime 2} \quad 3 a^{\prime \prime 2} 20 a^{\prime 2} 21 a^{\prime 2} 4 a^{\prime \prime 2} 22 a^{\prime 2} 23 a^{\prime 2} \quad 5 a^{\prime \prime 2}$ $24 a^{\prime 2} 6 a^{\prime \prime 2} 7 a^{\prime \prime} 25 a^{\prime 2}$ and for the $(g \pm, a)$ one: $\left[1 a^{2} 2 a^{2} 3 a^{2}\right.$ $\left.4 a^{2} 5 a^{2} \quad 6 a^{2} 7 a^{2}\right] \quad 8 a^{2} \quad 9 a^{2} 10 a^{2} 11 a^{2} 12 a^{2} 13 a^{2} 14 a^{2} 15 a^{2}$ $16 a^{2} 17 a^{2} 18 a^{2} 19 a^{2} 20 a^{2} 21 a^{2} 22 a^{2} 23 a^{2} 24 a^{2} 25 a^{2} 26 a^{2}$ $27 a^{2} 28 a^{2} 29 a^{2} 30 a^{2}$.

In all cases the HOMO, as in previously analyzed ester molecules, in the neutral ground state is localized predominantly on the terminal oxygen in-plane lone pair. In the case of methyl butyrate the HOMO is $\left(22 a^{\prime}\right)^{2}$ for the $(a, a)$ conformer and $(28 a)^{2}$ for the $(g \pm, a)$ one, whereas for methyl valerate the HOMO is $\left(25 a^{\prime}\right)^{2}$ for the $(a, a)$ conformer and $(30 a)^{2}$ for $(g \pm, a)$.

Since the distinct presence of both conformers contribute equally to the spectra, in this work we will refer to the states as the HOMO, HOMO-1, etc., meaning e.g. for HOMO of methyl butyrate both $\left(22 a^{\prime}\right)^{2}$ for $(a, a)$ conformer and $(28 a)^{2}$ for the $(g \pm, a)$ one.

\section{Results and discussion}

\subsection{Photoelectron spectra}

The photoelectron spectra of methyl butyrate and methyl valerate are shown in Figures 1 and 2. Based on the calculated values for both conformers, which are shown for methyl butyrate in Table 1 and methyl valerate in Table 2, it was possible to identify most of the ionization energies of 


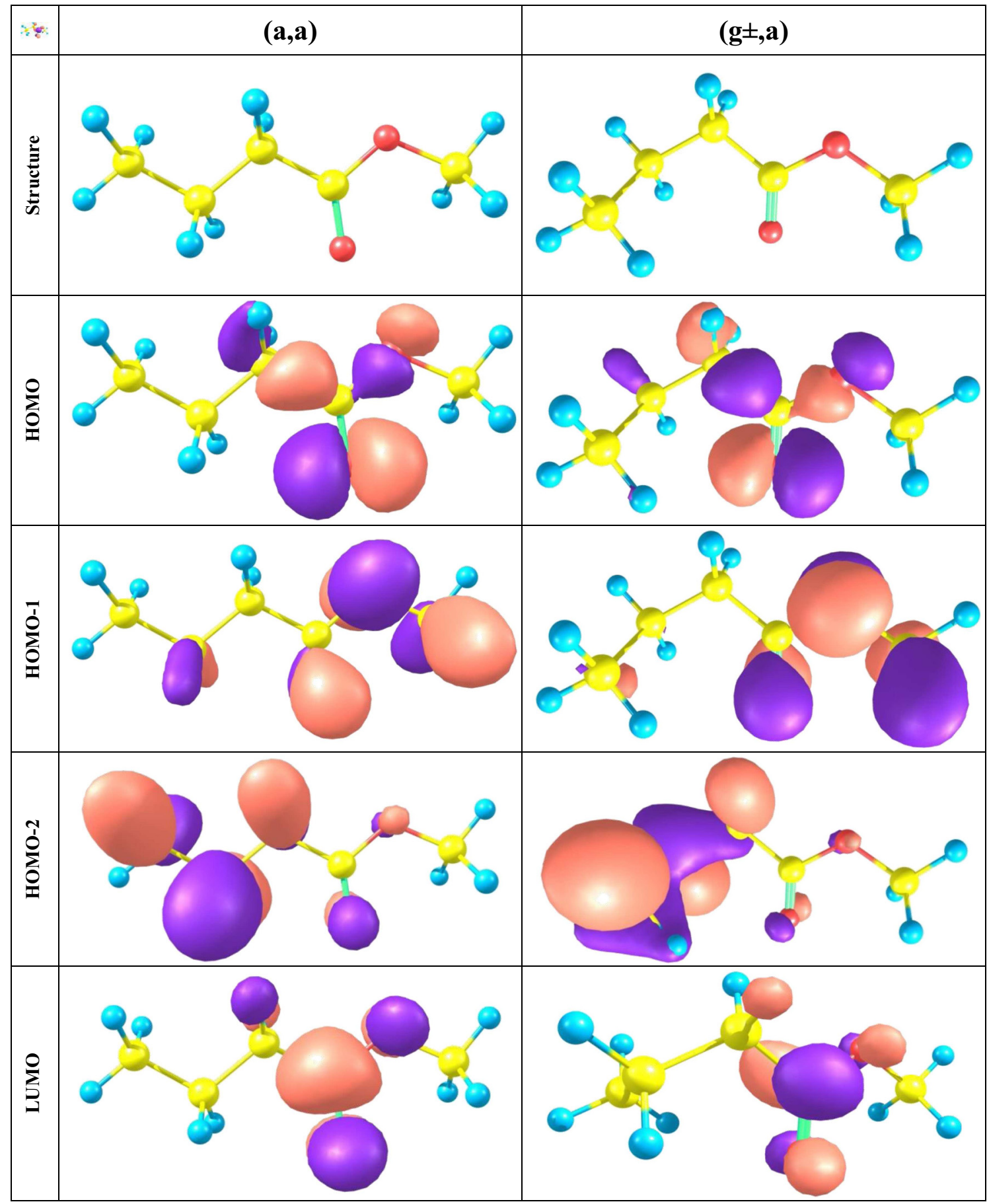

Fig. 5. The structure and HOMO, HOMO-1, HOMO-2, LUMO localization on both the $(a, a)$ and $(g \pm, a)$ conformers of methyl butyrate, $\mathrm{C}_{5} \mathrm{H}_{10} \mathrm{O}_{2}$.

both molecules. The values obtained based on the experimental spectra are also shown in the tables for comparison with the results of the calculations. The best accuracy was obtained for energies obtained from calculations using the P3+ method.

In the case of methyl butyrate it was not possible to resolve unambiguously the ionization energies of the third, fourth and fifth orbitals, since they appeared too close together. For methyl valerate it was the position of additional 2 orbitals for the $(a, a)$ conformer and one for $(g \pm, a)$ that were impossible to determine from the experimental spectrum.

The analysis of the first ionic state of both esters allowed not only the determination of the value of the first adiabatic and vertical ionization energies of the compounds, but also revealed a vibronic progression, similar to 


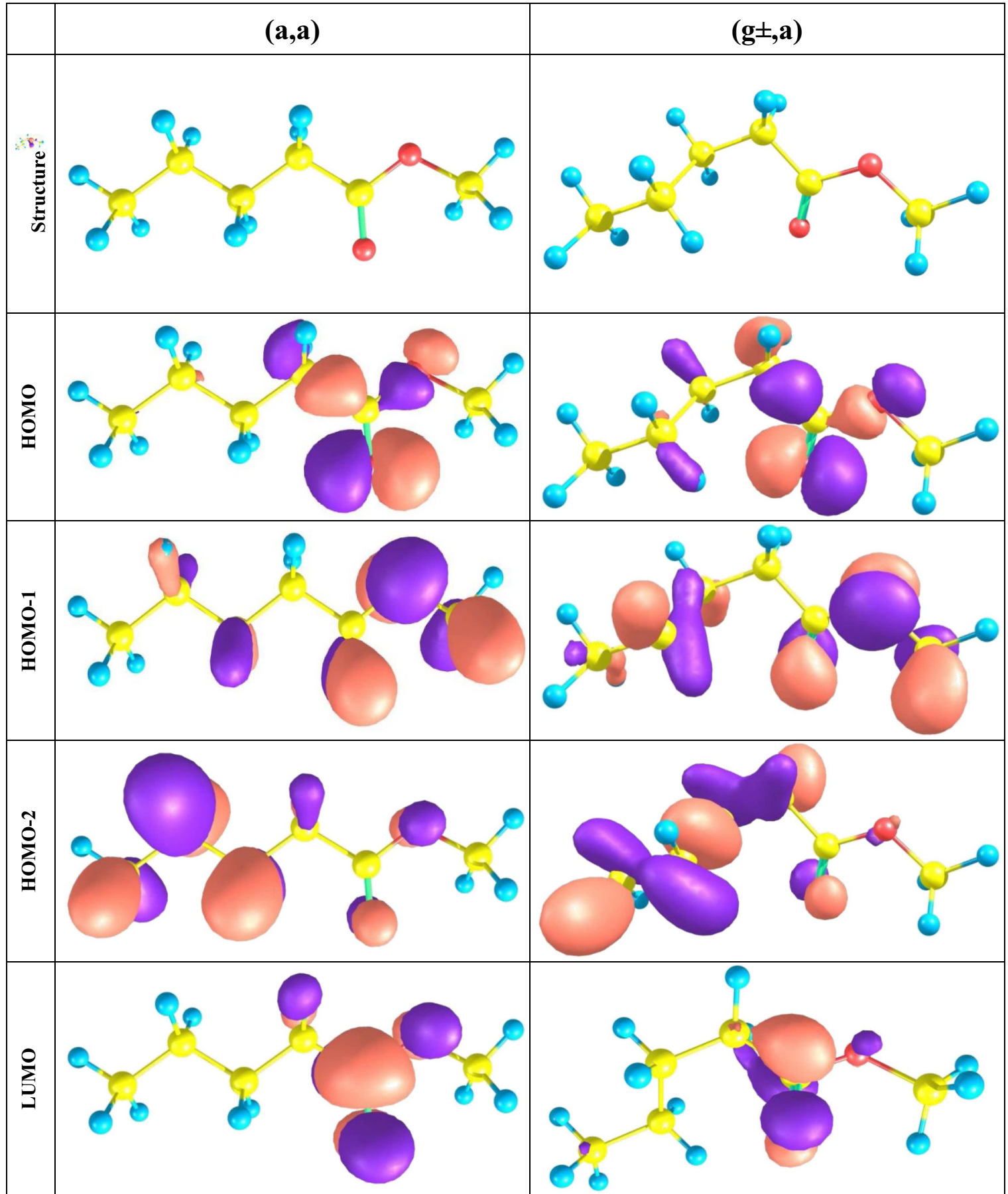

Fig. 6. The structure and HOMO, HOMO-1, HOMO-2, LUMO localization on both the $(a, a)$ and $(g \pm, a)$ conformers of methyl valerate, $\mathrm{C}_{6} \mathrm{H}_{12} \mathrm{O}_{2}$.

one seen for previous esters. This vibrational structure is depicted in Figure 7, top for methyl butyrate and bottom for methyl valerate. The obtained values are summarized in Table 3. With an average spacing of $\nu_{A}^{\prime}=0.153 \mathrm{eV}$ for methyl butyrate and $\nu_{A^{\prime}}^{\prime}=0.151 \mathrm{eV}$ for methyl valerate, the vibration corresponds to a combination of $\mathrm{C}-\mathrm{O}$ stretch combined with $\mathrm{C}=\mathrm{O}$ stretch, as found previously for other esters.

\subsection{Valence states, transitions and Rydberg series in photoabsorption spectra}

According to the calculations presented in Tables 4 and 5, the first absorption bands that are centered at $5.877 \mathrm{eV}$ for methyl butyrate and $5.883 \mathrm{eV}$ for methyl valerate (Figs. 3 and 4 ) correspond to the first $\mathrm{HOMO} \rightarrow \mathrm{LUMO}$ valence transition. 
Table 1. Calculated vertical ionization energies and pseudo-intensities (pole strengths, PS) of methyl butyrate for ( $a, a)$ and $(g \pm, a)$ symmetries at the M06-2X/aug-cc-pVTZ geometry calculated with propagator methods, compared with experimental values, all in $\mathrm{eV}$.

\begin{tabular}{|c|c|c|c|c|c|c|c|c|}
\hline \multirow[t]{2}{*}{ Configuration } & \multicolumn{7}{|c|}{ Calculated/eV } & \multirow[t]{2}{*}{ Experimental/eV } \\
\hline & Koopmans & OVGF & $\overline{\mathrm{PS}}$ & P3 & $\mathrm{PS}$ & $\mathrm{P} 3+$ & $\overline{P S}$ & \\
\hline \multicolumn{9}{|l|}{$(a, a)$} \\
\hline $22 a^{\prime-1}$ & 12.115 & 10.744 & 0.895 & 10.595 & 0.891 & 10.387 & 0.885 & 10.281 \\
\hline $5 a^{\prime \prime-1}$ & 12.541 & 11.460 & 0.899 & 11.359 & 0.894 & 11.224 & 0.890 & 11.002 \\
\hline $4 a^{\prime \prime-1}$ & 13.045 & 12.285 & 0.915 & 12.200 & 0.912 & 12.160 & 0.911 & - \\
\hline $21 a^{\prime-1}$ & 13.309 & 12.379 & 0.911 & 12.402 & 0.907 & 12.338 & 0.905 & - \\
\hline $20 a^{\prime-1}$ & 13.670 & 12.491 & 0.902 & 12.543 & 0.897 & 12.420 & 0.894 & - \\
\hline $19 a^{\prime-1}$ & 14.409 & 13.334 & 0.909 & 13.193 & 0.906 & 13.071 & 0.902 & 13.166 \\
\hline $4 a^{\prime \prime-1}$ & 14.155 & 13.274 & 0.905 & 13.202 & 0.900 & 13.138 & 0.898 & 13.166 \\
\hline $3 a^{\prime \prime-1}$ & 15.434 & 14.571 & 0.909 & 14.488 & 0.904 & 14.446 & 0.903 & 14.471 \\
\hline $18 a^{\prime-1}$ & 15.662 & 14.624 & 0.907 & 14.556 & 0.902 & 14.495 & 0.901 & 14.471 \\
\hline $17 a^{\prime-1}$ & 16.186 & 15.025 & 0.905 & 14.933 & 0.900 & 14.815 & 0.897 & 14.708 \\
\hline $2 a^{\prime \prime-1}$ & 17.334 & 16.026 & 0.907 & 16.014 & 0.899 & 15.953 & 0.897 & 15.692 \\
\hline $16 a^{\prime-1}$ & 18.321 & 16.518 & 0.893 & 16.510 & 0.890 & 16.268 & 0.881 & 16.202 \\
\hline $1 a^{\prime \prime-1}$ & 18.564 & 16.879 & 0.893 & 16.882 & 0.887 & 16.735 & 0.882 & 16.884 \\
\hline $15 a^{\prime-1}$ & 19.088 & 17.170 & 0.886 & 17.194 & 0.881 & 17.006 & 0.874 & 17.325 \\
\hline $14 a^{\prime-1}$ & 20.873 & 18.857 & 0.886 & 18.801 & 0.882 & 18.603 & 0.875 & 18.551 \\
\hline \multicolumn{9}{|l|}{$(g \pm, a)$} \\
\hline $28 a^{\prime-1}$ & 12.007 & 10.750 & 0.897 & 10.612 & 0.893 & 10.414 & 0.887 & 10.281 \\
\hline $27 a^{\prime-1}$ & 12.557 & 11.470 & 0.898 & 11.364 & 0.893 & 11.222 & 0.888 & 11.002 \\
\hline $25 a^{\prime-1}$ & 13.203 & 12.225 & 0.908 & 12.284 & 0.903 & 12.206 & 0.901 & - \\
\hline $26 a^{\prime-1}$ & 13.136 & 12.301 & 0.913 & 12.272 & 0.909 & 12.219 & 0.908 & - \\
\hline $24 a^{\prime-1}$ & 13.355 & 12.399 & 0.910 & 12.308 & 0.907 & 12.228 & 0.904 & - \\
\hline $23 a^{\prime-1}$ & 14.337 & 13.225 & 0.908 & 13.091 & 0.905 & 12.956 & 0.900 & 12.973 \\
\hline $22 a^{\prime-1}$ & 14.525 & 13.578 & 0.902 & 13.512 & 0.897 & 13.427 & 0.895 & 13.487 \\
\hline $21 a^{\prime-1}$ & 15.314 & 14.268 & 0.907 & 14.241 & 0.902 & 14.170 & 0.900 & 14.110 \\
\hline $20 a^{\prime-1}$ & 15.400 & 14.386 & 0.907 & 14.294 & 0.902 & 14.227 & 0.900 & 14.110 \\
\hline $19 a^{\prime-1}$ & 16.771 & 15.497 & 0.908 & 15.514 & 0.900 & 15.435 & 0.897 & 15.233 \\
\hline $18 a^{\prime-1}$ & 16.892 & 15.618 & 0.908 & 15.626 & 0.900 & 15.553 & 0.898 & 15.233 \\
\hline $17 a^{\prime-1}$ & 18.289 & 16.506 & 0.894 & 16.512 & 0.890 & 16.277 & 0.882 & 16.202 \\
\hline $16 a^{\prime-1}$ & 18.514 & 16.795 & 0.893 & 16.800 & 0.886 & 16.641 & 0.881 & 18.884 \\
\hline $15 a^{\prime-1}$ & 19.130 & 17.255 & 0.888 & 17.256 & 0.883 & 17.079 & 0.876 & 17.325 \\
\hline $14 a^{\prime-1}$ & 20.829 & 18.797 & 0.885 & 18.745 & 0.882 & 18.534 & 0.875 & 18.551 \\
\hline
\end{tabular}

The spectra of both molecules present distinct similarities in shape and energy position of detected transitions. Calculations reveal the highly mixed character of the transitions within the investigated range, thus there are no distinct features present, apart from the second band that was assigned to $\mathrm{HOMO} \rightarrow 3 s / \sigma^{*}$ and HOMO- $1 \rightarrow 3 s / \sigma^{*}$ transitions, localized on the $\mathrm{CH}$ bond in both compounds. The mixed character of the transitions together with the complexity of the molecules and continuous overlap of the states at higher energies made it difficult to perform any unambiguous assignments. In the case of methyl butyrate, apart from a few members of some Rydberg series, a shoulder feature, marked A, was assigned to the HOMO- $\rightarrow$ LUMO transition for the $(a, a)$ conformer together with a mixed transition $\mathrm{HOMO}-1 \rightarrow \mathrm{LUMO}+\mathrm{HOMO} \rightarrow 3 d$ for the $(g \pm, a)$ conformer, centered at $8.683 \mathrm{eV}$. A band labeled B at $9.124 \mathrm{eV}$ was identified either as HOMO- $3 \rightarrow 3 s / \sigma^{*}$ for $(a, a)$ or a mixed transition from HOMO-4 in $(g \pm, a)$. The structure centered at $9.311 \mathrm{eV}$ is most likely either another mixed transition from HOMO-4 orbital, but in $(a, a)$, or a $\mathrm{HOMO} \rightarrow 4 p$ one in $(g \pm, a)$.

Similarly, for methyl valerate, there are 3 bands $A^{\prime}, B^{\prime}$, $C^{\prime}$ marked in the spectrum. The first, at $8.562 \mathrm{eV}$, was also assigned to a combination of HOMO- $\rightarrow$ LUMO for the $(a, a)$ conformer together with a mixed transition HOMO$1 \rightarrow \mathrm{LUMO}+\mathrm{HOMO} \rightarrow 3 d$ for $(g \pm, a)$ conformer. The $B^{\prime}$ band was tentatively assigned at $8.744 \mathrm{eV}$ and corresponds to $\mathrm{HOMO}-1 \rightarrow 3 p \pi+\mathrm{HOMO} \rightarrow 3 d \sigma$ for the $(a, a)$ conformer mixed with $\mathrm{HOMO}-1 \rightarrow+\mathrm{HOMO}-3 \rightarrow 3 s \sigma / \sigma^{*}$ for $(g \pm, a)$ one. The last band $C^{\prime}$ at about $9.107 \mathrm{eV}$ was assigned based on the calculations to either a mixed transition from HOMO-2 in $(a, a)$ conformer or also a mixed one from HOMO-3 in $(g \pm, a)$ conformer.

The $\mathrm{HOMO} \rightarrow 3 s / \sigma^{*}$ transition in the case of both methyl butyrate and methyl valerate is associated with rather complex vibronic structure, marked for both esters in Figure 8. For both esters we identified three vibrational modes $\nu_{a}, \nu_{b}, \nu_{c}$ (labeled with prime for methyl valerate) with an average energy spacing of 180, 68 and $48 \mathrm{meV}$, 
Table 2. Calculated vertical ionization energies and pseudo-intensities (pole strengths PS) of methyl valerate for ( $a$, $a$ ) and $(g \pm, a)$ symmetries at the M06-2X/aug-cc-pVTZ geometry calculated with propagator methods, compared with experimental values, all in $\mathrm{eV}$.

\begin{tabular}{|c|c|c|c|c|c|c|c|c|}
\hline \multirow[t]{2}{*}{ Configuration } & \multicolumn{7}{|c|}{ Calculated/eV } & \multirow[t]{2}{*}{ Experimental/eV } \\
\hline & Koopmans & OVGF & PS & P3 & PS & $\mathrm{P} 3+$ & PS & \\
\hline \multicolumn{9}{|l|}{$(a, a)$} \\
\hline $25 a^{\prime-1}$ & 12.076 & 10.712 & 0.895 & 10.594 & 0.891 & 10.394 & 0.885 & 10.240 \\
\hline $7 a^{\prime \prime-1}$ & 12.516 & 11.456 & 0.901 & 11.354 & 0.895 & 11.228 & 0.892 & 11.000 \\
\hline $24 a^{\prime-1}$ & 12.943 & 11.916 & 0.905 & 11.900 & 0.901 & 11.803 & 0.898 & - \\
\hline $6 a^{\prime \prime-1}$ & 12.827 & 12.039 & 0.914 & 11.926 & 0.910 & 11.876 & 0.909 & - \\
\hline $5 a^{\prime \prime-1}$ & 13.088 & 12.026 & 0.905 & 12.092 & 0.900 & 11.999 & 0.897 & - \\
\hline $23 a^{\prime-1}$ & 13.596 & 12.735 & 0.910 & 12.662 & 0.906 & 12.616 & 0.905 & - \\
\hline $22 a^{\prime-1}$ & 14.308 & 13.201 & 0.909 & 13.069 & 0.905 & 12.942 & 0.901 & - \\
\hline $21 a^{\prime-1}$ & 14.660 & 13.609 & 0.905 & 13.551 & 0.901 & 13.471 & 0.898 & 13.457 \\
\hline $4 a^{\prime \prime-1}$ & 14.597 & 13.751 & 0.904 & 13.637 & 0.899 & 13.577 & 0.897 & 13.575 \\
\hline $20 a^{\prime-1}$ & 15.771 & 14.630 & 0.903 & 14.594 & 0.899 & 14.500 & 0.896 & 14.520 \\
\hline $19 a^{\prime-1}$ & 16.276 & 15.102 & 0.903 & 14.994 & 0.899 & 14.894 & 0.895 & 14.811 \\
\hline $3 a^{\prime \prime-1}$ & 16.087 & 15.003 & 0.911 & 15.002 & 0.902 & 14.961 & 0.901 & 14.811 \\
\hline $2 a^{\prime \prime-1}$ & 17.584 & 16.209 & 0.904 & 16.176 & 0.896 & 16.108 & 0.894 & 16.152 \\
\hline $18 a^{\prime-1}$ & 18.304 & 16.493 & 0.893 & 16.491 & 0.889 & 16.253 & 0.881 & 16.152 \\
\hline $1 a^{\prime \prime-1}$ & 18.572 & 16.886 & 0.893 & 16.882 & 0.886 & 16.740 & 0.881 & 18.84 \\
\hline $17 a^{\prime-1}$ & 18.989 & 17.054 & 0.886 & 17.063 & 0.881 & 16.874 & 0.874 & 18.84 \\
\hline $16 a^{\prime-1}$ & 20.880 & 18.848 & 0.886 & 18.788 & 0.882 & 18.590 & 0.875 & 18.501 \\
\hline \multicolumn{9}{|l|}{$(g \pm, a)$} \\
\hline $32 a^{\prime-1}$ & 12.041 & 10.746 & 0.897 & 10.611 & 0.894 & 10.424 & 0.888 & 10.240 \\
\hline $31 a^{\prime-1}$ & 12.497 & 11.445 & 0.901 & 11.347 & 0.895 & 11.223 & 0.892 & 11.000 \\
\hline $30 a^{\prime-1}$ & 12.631 & 11.639 & 0.905 & 11.673 & 0.900 & 11.578 & 0.897 & 11.489 \\
\hline $29 a^{\prime-1}$ & 12.855 & 11.989 & 0.912 & 11.896 & 0.908 & 11.831 & 0.906 & - \\
\hline $28 a^{\prime-1}$ & 13.037 & 12.009 & 0.906 & 12.009 & 0.902 & 11.916 & 0.899 & - \\
\hline $27 a^{\prime-1}$ & 13.924 & 12.989 & 0.909 & 12.895 & 0.905 & 12.833 & 0.903 & - \\
\hline $26 a^{\prime-1}$ & 14.146 & 13.053 & 0.906 & 12.979 & 0.902 & 12.870 & 0.898 & - \\
\hline $25 a^{\prime-1}$ & 14.497 & 13.530 & 0.908 & 13.378 & 0.904 & 13.293 & 0.902 & 13.305 \\
\hline $24 a^{\prime-1}$ & 14.682 & 13.697 & 0.902 & 13.638 & 0.897 & 13.556 & 0.895 & 13.575 \\
\hline $23 a^{\prime-1}$ & 15.799 & 14.717 & 0.904 & 14.647 & 0.900 & 14.567 & 0.897 & 14.520 \\
\hline $22 a^{\prime-1}$ & 15.978 & 14.853 & 0.904 & 14.745 & 0.900 & 14.662 & 0.897 & 14.520 \\
\hline $21 a^{\prime-1}$ & 16.523 & 15.277 & 0.907 & 15.314 & 0.898 & 15.254 & 0.897 & 15.402 \\
\hline $20 a^{\prime-1}$ & 17.190 & 15.857 & 0.906 & 15.828 & 0.898 & 15.748 & 0.895 & 15.768 \\
\hline $19 a^{\prime-1}$ & 18.307 & 16.503 & 0.893 & 16.501 & 0.889 & 16.263 & 0.881 & 16.152 \\
\hline $18 a^{\prime-1}$ & 18.476 & 16.736 & 0.892 & 16.734 & 0.885 & 16.574 & 0.880 & 18.84 \\
\hline $17 a^{\prime-1}$ & 19.147 & 17.256 & 0.887 & 17.250 & 0.882 & 17.076 & 0.875 & 17.335 \\
\hline $16 a^{\prime-1}$ & 20.829 & 18.789 & 0.885 & 18.728 & 0.881 & 18.524 & 0.874 & 18.501 \\
\hline
\end{tabular}

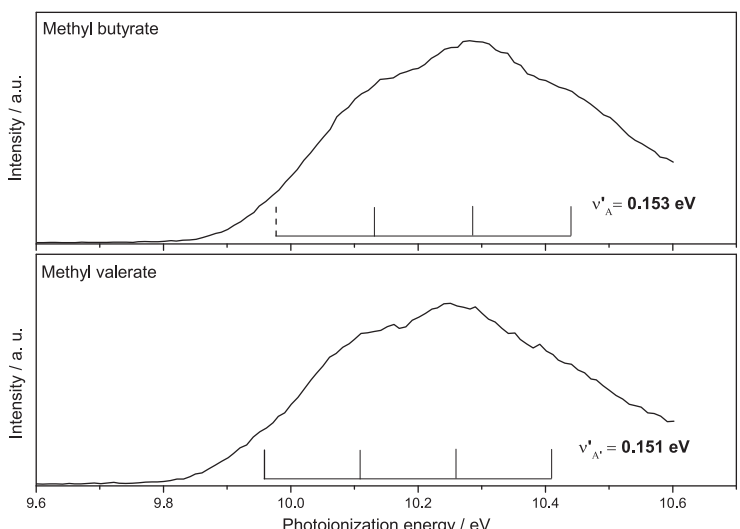

Fig. 7. First band of photoelectron spectrum of methyl butyrate, $\mathrm{C}_{5} \mathrm{H}_{10} \mathrm{O}_{2}$ (top) and methyl valerate, $\mathrm{C}_{6} \mathrm{H}_{12} \mathrm{O}_{2}$ (bottom), in the $9.6-10.7 \mathrm{eV}$ region, collected at $80 \mathrm{eV}$ initial photon energy with the most intense vibrational modes $\nu_{A}^{\prime}$ and $\nu_{A^{\prime}}^{\prime}$ resolved, respectively.
Table 3. Experimental values of adiabatic and vertical ionization energies of methyl butyrate and methyl valerate together with the vibrational mode $\nu_{A}^{\prime}$ that can be distinguished in the first ionization band, all in $\mathrm{eV}$.

\begin{tabular}{lcc}
\hline & Methyl butyrate & Methyl valerate \\
\hline Adiabatic & 9.977 & 9.959 \\
Vertical & 10.286 & 10.259 \\
$\nu_{A}^{\prime}$ & 0.153 & 0.151 \\
\hline
\end{tabular}

respectively. The first mode, $\nu_{a}$, is present in all PA spectra of esters and corresponds to the most distinct vibration, resulting from the combination of $\mathrm{C}-\mathrm{O}$ and $\mathrm{C}=\mathrm{O}$ stretch. The $\nu_{b}$ mode is most likely to be $\mathrm{O}=\mathrm{C}-\mathrm{O}$ deformation combined with a $\mathrm{C}-\mathrm{O}$ stretch. A similar structure with an energy spacing of c.a. $90 \mathrm{meV}$ was seen in the spectrum of ethyl formate [9]. The mode of average spacing of $48 \mathrm{meV}, \nu_{c}$, is ascribed to an OCC out-of-plane bend, 
Table 4. Calculated electronic spectrum of methyl butyrate for $(a, a)$ and $(g \pm, a)$ symmetries, compared with experimental values.

\begin{tabular}{|c|c|c|c|c|c|}
\hline State & $E / \mathrm{eV}$ & $f_{L}$ & Main character & Mixed & Exp./eV \\
\hline \multicolumn{6}{|l|}{$(a, a)$} \\
\hline${ }^{1} A^{\prime \prime}$ & 5.816 & 0.0005 & $22 a^{\prime} \rightarrow$ LUMO & & 5.877 \\
\hline${ }^{1} A^{\prime}$ & 7.452 & 0.0150 & $22 a^{\prime} \rightarrow 3 s / \sigma^{*}(\mathrm{CH})$ & & 7.557 \\
\hline${ }^{1} A^{\prime \prime}$ & 7.987 & 0.0119 & $5 a^{\prime \prime} \rightarrow 3 s / \sigma^{*}(\mathrm{CH})$ & & 7.882 \\
\hline${ }^{1} A^{\prime \prime}$ & 8.089 & 0.0001 & $22 a^{\prime} \rightarrow 3 p \pi$ & & \\
\hline${ }^{1} A^{\prime}$ & 8.146 & 0.0102 & $22 a^{\prime} \rightarrow 3 p \sigma$ & & \\
\hline${ }^{1} A^{\prime}$ & 8.222 & 0.0212 & $22 a^{\prime} \rightarrow 3 p \sigma$ & & \\
\hline${ }^{1} A^{\prime}$ & 8.332 & 0.0626 & $5 a^{\prime \prime} \rightarrow \mathrm{LUMO}$ & & 8.683 \\
\hline${ }^{1} A^{\prime \prime}$ & 8.481 & $<0.0001$ & $4 a^{\prime \prime} \rightarrow 3 s / \sigma^{*}(\mathrm{CH})$ & & \\
\hline${ }^{1} A^{\prime}$ & 8.549 & 0.0068 & $22 a^{\prime} \rightarrow 3 d \sigma$ & & \\
\hline${ }^{1} A^{\prime \prime}$ & 8.653 & 0.0118 & $5 a^{\prime \prime} \rightarrow 3 p \sigma$ & & \\
\hline${ }^{1} A^{\prime}$ & 8.741 & 0.0096 & $5 a^{\prime \prime} \rightarrow 3 p \pi$ & & \\
\hline${ }^{1} A^{\prime}$ & 8.793 & 0.0065 & $22 a^{\prime} \rightarrow 3 d \sigma$ & & \\
\hline${ }^{1} A^{\prime \prime}$ & 8.799 & 0.0016 & & $\mathrm{HOMO}-4 \rightarrow \mathrm{LUMO}+\mathrm{HOMO} \rightarrow 3 d \pi$ & \\
\hline${ }^{1} A^{\prime \prime}$ & 8.810 & $<0.0001$ & $5 a^{\prime \prime} \rightarrow 3 p \sigma$ & & \\
\hline${ }^{1} A^{\prime \prime}$ & 8.828 & 0.0003 & & $\mathrm{HOMO}-4 \rightarrow \mathrm{LUMO}+\mathrm{HOMO} \rightarrow 3 d \pi$ & \\
\hline${ }^{1} A^{\prime}$ & 8.849 & 0.0114 & $21 a^{\prime} \rightarrow 3 s / \sigma^{*}(\mathrm{CH})$ & & 9.124 \\
\hline${ }^{1} A^{\prime}$ & 8.886 & 0.0049 & $22 a^{\prime} \rightarrow 3 d \sigma$ & & \\
\hline${ }^{1} A^{\prime \prime}$ & 8.964 & 0.0001 & $22 a^{\prime} \rightarrow 3 d \pi$ & & \\
\hline${ }^{1} A^{\prime \prime}$ & 9.087 & 0.0012 & $5 a^{\prime \prime} \rightarrow 3 d \sigma$ & & \\
\hline${ }^{1} A^{\prime}$ & 9.091 & 0.0209 & $22 a^{\prime} \rightarrow 4 s \sigma$ & & 9.05 \\
\hline${ }^{1} A^{\prime}$ & 9.105 & 0.0055 & & $\mathrm{HOMO}-4 \rightarrow 3 s / \sigma^{*}(\mathrm{CH})+\mathrm{HOMO} \rightarrow 4 p \sigma$ & \\
\hline${ }^{1} A^{\prime \prime}$ & 9.147 & 0.0192 & $4 a^{\prime \prime} \rightarrow 3 p \pi$ & & \\
\hline${ }^{1} A^{\prime}$ & 9.149 & 0.0737 & & $\mathrm{HOMO}-4 \rightarrow 3 s / \sigma^{*}(\mathrm{CH})+\mathrm{HOMO}-2 \rightarrow 4 p \pi$ & 9.311 \\
\hline${ }^{1} A^{\prime \prime}$ & 9.161 & $<0.0001$ & $22 a^{\prime} \rightarrow 4 p \pi$ & & \\
\hline${ }^{1} A^{\prime}$ & 9.180 & 0.0116 & $22 a^{\prime} \rightarrow 4 p \sigma$ & & \\
\hline \multicolumn{6}{|l|}{$(g \pm, a)$} \\
\hline${ }^{1} A$ & 5.808 & 0.0007 & $28 a \rightarrow$ LUMO & & 5.877 \\
\hline${ }^{1} A$ & 7.497 & 0.0118 & $28 a \rightarrow 3 s / \sigma^{*}(\mathrm{CH})$ & & 7.557 \\
\hline${ }^{1} A$ & 8.025 & 0.0141 & $27 a \rightarrow 3 s / \sigma^{*}(\mathrm{CH})$ & & 7.882 \\
\hline${ }^{1} A$ & 8.069 & 0.0031 & $28 a \rightarrow 3 p$ & & \\
\hline${ }^{1} A$ & 8.132 & 0.0040 & $28 a \rightarrow 3 p$ & & \\
\hline${ }^{1} A$ & 8.225 & 0.0229 & $28 a \rightarrow 3 p$ & & \\
\hline${ }^{1} A$ & 8.312 & 0.0505 & & $\mathrm{HOMO}-1 \rightarrow \mathrm{LUMO}+\mathrm{HOMO} \rightarrow 3 d$ & 8.683 \\
\hline${ }^{1} A$ & 8.532 & 0.0372 & $28 a \rightarrow 3 d$ & & \\
\hline${ }^{1} A$ & 8.636 & 0.0083 & $27 a \rightarrow 3 p$ & & \\
\hline${ }^{1} A$ & 8.695 & 0.0033 & & $\mathrm{HOMO}-2 \rightarrow 3 s / \sigma^{*}(\mathrm{CH})+\mathrm{HOMO}-1 \rightarrow 3 p$ & \\
\hline${ }^{1} A$ & 8.742 & 0.0031 & & $\mathrm{HOMO}-4 \rightarrow \mathrm{LUMO}+\mathrm{HOMO} \rightarrow 3 d$ & \\
\hline${ }^{1} A$ & 8.764 & 0.0095 & & $\mathrm{HOMO}-1 \rightarrow 3 p+\mathrm{HOMO} \rightarrow 3 d$ & \\
\hline${ }^{1} A$ & 8.775 & 0.0040 & & $\mathrm{HOMO} \rightarrow 3 d+\mathrm{HOMO}-1 \rightarrow 3 p$ & \\
\hline${ }^{1} A$ & 8.800 & 0.0079 & $28 a \rightarrow 3 d$ & & \\
\hline${ }^{1} A$ & 8.809 & 0.0107 & $25 a \rightarrow 3 s / \sigma^{*}(\mathrm{CH})$ & & \\
\hline${ }^{1} A$ & 8.841 & 0.0216 & & $\mathrm{HOMO}-4 \rightarrow 3 s / \sigma^{*}(\mathrm{CH})+\mathrm{HOMO}-1 \rightarrow 3 p$ & 9.124 \\
\hline${ }^{1} A$ & 8.899 & 0.0016 & $28 a \rightarrow 3 d$ & & \\
\hline${ }^{1} A$ & 8.902 & 0.0026 & $28 a \rightarrow 3 d$ & & \\
\hline${ }^{1} A$ & 8.948 & 0.0007 & $28 a \rightarrow 4 s$ & & \\
\hline${ }^{1} A$ & 9.044 & 0.0034 & $28 a \rightarrow 4 p$ & & \\
\hline${ }^{1} A$ & 9.110 & 0.0103 & $27 a \rightarrow 3 d$ & & \\
\hline${ }^{1} A$ & 9.133 & 0.0439 & $26 a \rightarrow 3 p$ & & 9.311 \\
\hline${ }^{1} A$ & 9.148 & 0.0040 & $28 a \rightarrow 4 p$ & & \\
\hline${ }^{1} A$ & 9.171 & 0.0220 & & $\mathrm{HOMO} \rightarrow 4 p+\mathrm{HOMO}-3 \rightarrow 3 p$ & \\
\hline${ }^{1} A$ & 9.183 & 0.0078 & $28 a \rightarrow 4 p$ & & \\
\hline
\end{tabular}


Table 5. Calculated electronic spectrum of methyl valerate for $(a, a)$ and $(g \pm, a)$ symmetries, compared with experimental values.

\begin{tabular}{|c|c|c|c|c|c|}
\hline State & $E / \mathrm{eV}$ & $f_{L}$ & Main character & Mixed & Exp./eV \\
\hline \multicolumn{6}{|l|}{$(a, a)$} \\
\hline${ }^{1} A^{\prime \prime}$ & 5.817 & 0.0005 & $25 a^{\prime} \rightarrow \mathrm{LUMO}$ & & 5.883 \\
\hline${ }^{1} A^{\prime}$ & 7.449 & 0.0127 & $25 a^{\prime} \rightarrow 3 s \sigma / \sigma^{*}(\mathrm{CH})$ & & 7.478 \\
\hline${ }^{1} A^{\prime \prime}$ & 7.983 & 0.0111 & $7 a^{\prime \prime} \rightarrow 3 s \sigma / \sigma^{*}(\mathrm{CH})$ & & 7.852 \\
\hline${ }^{1} A^{\prime \prime}$ & 8.063 & $<0.0001$ & $25 a^{\prime} \rightarrow 3 p \pi$ & & \\
\hline${ }^{1} A^{\prime}$ & 8.127 & 0.0017 & $25 a^{\prime} \rightarrow 3 p \sigma$ & & \\
\hline${ }^{1} A^{\prime}$ & 8.207 & 0.0080 & $25 a^{\prime} \rightarrow 3 p \sigma$ & & \\
\hline${ }^{1} A^{\prime \prime}$ & 8.322 & 0.0002 & $6 a^{\prime \prime} \rightarrow 3 s \sigma / \sigma^{*}(\mathrm{CH})$ & & \\
\hline${ }^{1} A^{\prime}$ & 8.327 & 0.0676 & $7 a^{\prime \prime} \rightarrow \mathrm{LUMO}$ & & 8.562 \\
\hline${ }^{1} A^{\prime}$ & 8.465 & 0.0392 & $7 a^{\prime \prime} \rightarrow 3 p \sigma$ & & \\
\hline${ }^{1} A^{\prime}$ & 8.608 & 0.0019 & & $\mathrm{HOMO} \rightarrow 3 d \sigma+\mathrm{HOMO}-3 \rightarrow 3 p \sigma$ & \\
\hline${ }^{1} A^{\prime \prime}$ & 8.631 & 0.0068 & $7 a^{\prime \prime} \rightarrow 3 p \sigma$ & & \\
\hline${ }^{1} A^{\prime}$ & 8.714 & 0.0199 & & $\mathrm{HOMO}-1 \rightarrow 3 p \pi+\mathrm{HOMO} \rightarrow 3 d \sigma$ & 8.744 \\
\hline${ }^{1} A^{\prime \prime}$ & 8.728 & 0.0012 & & $\mathrm{HOMO} \rightarrow 3 p \pi+\mathrm{HOMO}-3 \rightarrow \mathrm{LUMO}$ & \\
\hline${ }^{1} A^{\prime}$ & 8.728 & 0.0045 & & $\mathrm{HOMO} \rightarrow 3 d \sigma+\mathrm{HOMO}-1 \rightarrow 3 p \pi$ & \\
\hline${ }^{1} A^{\prime}$ & 8.777 & 0.0045 & $5 a^{\prime \prime} \rightarrow 3 s \sigma / \sigma^{*}(\mathrm{CH})$ & & \\
\hline${ }^{1} A^{\prime \prime}$ & 8.784 & 0.0002 & & $\mathrm{HOMO}-3 \rightarrow \mathrm{LUMO}+\mathrm{HOMO} \rightarrow 3 d \pi$ & \\
\hline${ }^{1} A^{\prime \prime}$ & 8.797 & 0.0014 & & $\mathrm{HOMO}-1 \rightarrow 3 d \sigma+\mathrm{HOMO}-3 \rightarrow \mathrm{LUMO}$ & \\
\hline${ }^{1} A^{\prime}$ & 8.842 & 0.0049 & $25 a^{\prime} \rightarrow 3 d \sigma$ & & \\
\hline${ }^{1} A^{\prime \prime}$ & 8.876 & 0.0044 & $5 a^{\prime \prime} \rightarrow 3 s \sigma / \sigma^{*}(\mathrm{CH})$ & & \\
\hline${ }^{1} A^{\prime}$ & 8.926 & 0.0605 & & HOMO $-2 \rightarrow 3 p \pi+$ HOMO- $1 \rightarrow 3 p \pi$ & 9.012 \\
\hline${ }^{1} A^{\prime \prime}$ & 8.939 & 0.0002 & $25 a^{\prime} \rightarrow 3 d \pi$ & & \\
\hline${ }^{1} A^{\prime \prime}$ & 8.966 & 0.0570 & & HOMO- $2 \rightarrow 3 p \sigma+$ HOMO- $1 \rightarrow 3 d \sigma$ & 9.107 \\
\hline${ }^{1} A^{\prime}$ & 9.019 & 0.0085 & & $\mathrm{HOMO}-3 \rightarrow 3 d \sigma+\mathrm{HOMO}-4 \rightarrow 3 p \sigma$ & \\
\hline${ }^{1} A^{\prime \prime}$ & 9.074 & 0.0093 & $24 a^{\prime} \rightarrow 3 p \pi$ & & \\
\hline${ }^{1} A^{\prime}$ & 9.102 & 0.0078 & & $\mathrm{HOMO} \rightarrow 3 d \sigma+\mathrm{HOMO}-3 \rightarrow 3 p \sigma$ & \\
\hline \multicolumn{6}{|c|}{$(g \pm, a)$} \\
\hline${ }^{1} A$ & 5.812 & 0.0007 & $30 a \rightarrow$ LUMO & & 5.883 \\
\hline${ }^{1} A$ & 7.506 & 0.0120 & $30 a \rightarrow 3 s \sigma / \sigma^{*}(\mathrm{CH})$ & & 7.574 \\
\hline${ }^{1} A$ & 8.016 & 0.0122 & $29 a \rightarrow 3 s \sigma / \sigma^{*}(\mathrm{CH})$ & & 7.962 \\
\hline${ }^{1} A$ & 8.05 & 0.0024 & $30 a \rightarrow 3 p$ & & \\
\hline${ }^{1} A$ & 8.104 & 0.0020 & $30 a \rightarrow 3 p$ & & \\
\hline${ }^{1} A$ & 8.188 & 0.0141 & $30 a \rightarrow 3 p$ & & \\
\hline${ }^{1} A$ & 8.304 & 0.0643 & & $\mathrm{HOMO}-1 \rightarrow \mathrm{LUMO}+\mathrm{HOMO} \rightarrow 3 d$ & 8.562 \\
\hline${ }^{1} A$ & 8.399 & 0.0018 & $28 a \rightarrow 3 s \sigma / \sigma^{*}(\mathrm{CH})$ & & \\
\hline${ }^{1} A$ & 8.422 & 0.0231 & & $\mathrm{HOMO}-3 \rightarrow 3 s \sigma / \sigma^{*}(\mathrm{CH})+\mathrm{HOMO} \rightarrow 3 d$ & \\
\hline${ }^{1} A$ & 8.526 & 0.0231 & & $\mathrm{HOMO} \rightarrow 3 d+\mathrm{HOMO}-3 \rightarrow 3 s \sigma / \sigma^{*}(\mathrm{CH})$ & \\
\hline${ }^{1} A$ & 8.648 & 0.0076 & $29 a \rightarrow 3 p$ & & \\
\hline${ }^{1} A$ & 8.663 & 0.0066 & $29 a \rightarrow 3 p$ & & \\
\hline${ }^{1} A$ & 8.709 & 0.0040 & $30 a \rightarrow 3 d$ & & \\
\hline${ }^{1} A$ & 8.720 & 0.0180 & & $\mathrm{HOMO}-1 \rightarrow 3 p+\mathrm{HOMO}-3 \rightarrow 3 s \sigma / \sigma^{*}(\mathrm{CH})$ & 8.744 \\
\hline${ }^{1} A$ & 8.758 & 0.0038 & & $\mathrm{HOMO}-5 \rightarrow \mathrm{LUMO}+\mathrm{HOMO}-4 \rightarrow 3 s \sigma / \sigma^{*}(\mathrm{CH})$ & \\
\hline${ }^{1} A$ & 8.776 & 0.0069 & & $\mathrm{HOMO}-1 \rightarrow 3 p+\mathrm{HOMO}-3 \rightarrow 3 s \sigma / \sigma^{*}(\mathrm{CH})$ & \\
\hline${ }^{1} A$ & 8.814 & 0.0198 & & $\mathrm{HOMO} \rightarrow 3 d+\mathrm{HOMO}-2 \rightarrow \mathrm{LUMO}$ & \\
\hline${ }^{1} A$ & 8.846 & 0.0020 & $30 a \rightarrow 3 d$ & & \\
\hline${ }^{1} A$ & 8.877 & 0.0015 & $30 a \rightarrow 3 d$ & & \\
\hline${ }^{1} A$ & 8.883 & 0.0022 & & $\begin{array}{l}\mathrm{HOMO} \rightarrow \\
3 s \sigma / \sigma^{*}(\mathrm{CH})\end{array} 3 d+$ HOMO-1 $\rightarrow 3 d+$ HOMO-3 $\rightarrow$ & \\
\hline${ }^{1} A$ & 8.911 & 0.0106 & & $\mathrm{HOMO}-3 \rightarrow 3 p+\mathrm{HOMO}-1 \rightarrow 3 d$ & \\
\hline${ }^{1} A$ & 8.915 & 0.0123 & & $\mathrm{HOMO}-2 \rightarrow 3 p+\mathrm{HOMO} \rightarrow 3 d$ & \\
\hline${ }^{1} A$ & 8.947 & 0.0575 & & $\mathrm{HOMO}-3 \rightarrow 3 p+\mathrm{HOMO}-1 \rightarrow 3 d$ & 9.012 \\
\hline${ }^{1} A$ & 8.991 & 0.0110 & $28 a \rightarrow 3 p$ & & \\
\hline${ }^{1} A$ & 9.032 & 0.0248 & & $\mathrm{HOMO} \rightarrow 4 s+\mathrm{HOMO}-3 \rightarrow 3 p+\mathrm{HOMO}-1 \rightarrow 3 d$ & 9.107 \\
\hline
\end{tabular}




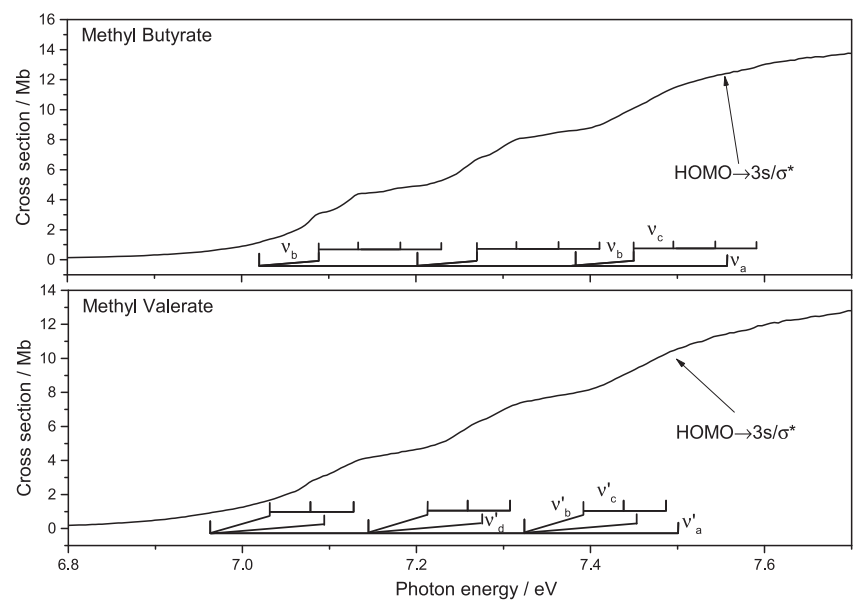

Fig. 8. First band of photoabsorption spectrum of methyl butyrate, $\mathrm{C}_{5} \mathrm{H}_{10} \mathrm{O}_{2}$ (top) and methyl valerate, $\mathrm{C}_{6} \mathrm{H}_{12} \mathrm{O}_{2}$ (bottom), in the $6.8-7.8 \mathrm{eV}$ range with the most intense vibrational modes $\nu_{a}, \nu_{b}, \nu_{c}$ and $\nu_{a^{\prime}}, \nu_{b^{\prime}}, \nu_{c^{\prime}}$ and $\nu_{d^{\prime}}$ resolved, respectively.

seen in the PA spectrum of isuobutyl acetate [10]. For methyl valerate we also resolved a $\nu_{d}^{\prime}$ mode of $130 \mathrm{meV}$ and assigned this to skeletal $\mathrm{C}-\mathrm{C}$ stretching, which was also observed in methyl and ethyl formates $[8,9]$.

In the photoabsorption spectrum of methyl valerate, a series of three peaks, evenly spaced with $\nu_{\alpha}=144 \mathrm{meV}$ appear at about $6.5 \mathrm{eV}$ (Fig. 4). Such feature has not been observed previously for other ester molecules [8-12]. This series may be an additional vibrational mode, such as a series of $\mathrm{C}-\mathrm{C}$ skeletal stretching, already seen here as $\nu_{d}$ associated with the $\nu_{a}$ mode.

Over the whole range of the photoabsorption spectrum investigated, only the first two members of the Rydberg series converging to the two highest ionic states were resolved, mainly due to state overlap as a result of the presence of the two conformers for each compound. The other transitions were assigned based purely on the results from the computer calculations and the value of the oscillator strength, since it was not possible to unambiguously determine the value of the ionization energy from HOMO-2, HOMO-3 and HOMO-4 for both esters. The resolved states are marked in Figure 3 for methyl butyrate and Figure 4.

The values obtained for Rydberg series converging to the first two ionization energies are summarized in Table 6 with the value of the quantum defect calculated using the well-known Rydberg formula. As for previously investigated esters, the $n s$ series values of $\delta$ are between 0.7 and 0.9 for members of all transition families with the quantum defect values being higher for the transitions converging to HOMO-1 ionization band than those converging to the HOMO.

\subsection{Atmospheric photolysis}

There is a very little information on the possible interaction of free radicals with methyl butyrate and methyl valerate. There is also no information in the literature on the photolysis rate and thus the lifetimes of these esters in the upper atmosphere. Therefore, the present absolute cross sections can be used in combination with solar actinic flux [34] measurements from the literature to estimate the photolysis rate of both methyl esters in the atmosphere from an altitude close to the ground, to the stratopause at $50 \mathrm{~km}$. Details of the calculation programme were published previously [35] and the quantum yield for dissociation following absorption in that programme is assumed to be unity. The reciprocal of the photolysis rate at a given altitude corresponds to the local photolysis lifetime.

Photolysis lifetimes of less than 1 sunlit day were calculated at altitudes above $30 \mathrm{~km}$ for methyl butyrate, which means that the molecules can be broken up quite efficiently by VUV absorption above this altitude. Also at ground level the lifetimes are shorter than one day. UV photolysis is therefore expected to play a significant role in the tropospheric and stratospheric removal of methyl butyrate.

For both methyl butyrate and methyl valerate the stratospheric lifetime is long, about 6 days at $30 \mathrm{~km}$. The lifetimes at $10 \mathrm{~km}$ are extremely long for these molecules, reaching thousands of years. Therefore, photolysis will not be the main sink mechanism for the removal of the molecules from the atmosphere. This is similar to previously analyzed esters, ethyl and methyl formate, for which UV photolysis was also not expected to play a significant role, but in contrast to isobutyl formate, where photolysis may be a major removal mechanism.

The only relevant investigations found for these esters presented kinetic studies of hydroxyl radical reactions [36]. The lifetimes obtained there with typical tropospheric $\mathrm{OH}$ concentrations of $10^{6}$ molecules per $\mathrm{cm}^{3}$ yielded 3.5 days for methyl butyrate and 2.4 days for methyl valerate. This would certainly suggest that the reaction with $\mathrm{OH}$ radical would be a prevalent sink mechanism for both methyl butyrate and methyl valerate.

\section{Conclusions}

For the first time the complete electronic spectra of methyl butyrate and methyl valerate are presented here together with absolute photoabsorption cross sections from 4.5 to $10.8 \mathrm{eV}$. The structures that can be observed in the spectrum can be assigned to both valence and Rydberg transitions, based on ab initio calculations of vertical excitation energies and oscillator strengths of these molecules. Fine structure, that was resolved both in the photoelectron and photoabsorption spectra, has been assigned to vibrational series involving, predominantly, excitations of c.a. $180 \mathrm{meV}$, attributed to $\mathrm{C}=\mathrm{O}$ and $\mathrm{C}-\mathrm{O}$ stretching. Other vibrations resolved in the photoabsorption spectrum of both molecules correspond to further stretches and deformations that were also seen in the previously analyzed molecules. The theoretical calculations presented here are in good agreement with experimental data. The photoabsorption cross sections were used to calculate the photolysis lifetimes of methyl butyrate and methyl valerate for the Earth's troposphere and stratosphere. From this and 
Table 6. Energies (eV), quantum defects and assignments of the $n s$ Rydberg series converging to the first two ionic electronic ground state of methyl butyrate and methyl valerate.

\begin{tabular}{lcc}
\hline Vertical transition energy/eV & Quantum defect, $\delta$ & Assignment \\
\hline Methyl butyrate & & \\
& $\mathrm{IE}_{1}=10.286 \mathrm{eV}$ & \\
7.56 & 0.77 & $3 s \sigma^{*}$ \\
9.05 & 0.87 & $4 s \sigma$ \\
& $\mathrm{IE}_{2}=11.002 \mathrm{eV}$ & \\
7.88 & 0.91 & $3 s \sigma^{*}$ \\
9.60 & 0.88 & $4 s \sigma$ \\
\hline Methyl valerate & & \\
7.48 & $\mathrm{IE}_{1}=10.259 \mathrm{eV}$ & $3 s \sigma^{*}$ \\
8.99 & 0.79 & $4 s \sigma$ \\
7.85 & 0.73 & $3 s \sigma^{*}$ \\
9.57 & $\mathrm{IE}_{2}=11.000 \mathrm{eV}$ & $4 s \sigma$ \\
\hline
\end{tabular}

comparing our results with those obtained from kinetic studies of reaction with hydroxyl radicals, we conclude that photolysis is not a leading removal mechanism for either methyl butyrate or methyl valerate.

We would like to express our gratitude to Dr. H.V.L. Nguyen for sharing her unpublished results with us. We are grateful to Dr. S. Caprasecca for his initial involvement in this work. The authors wish to acknowledge the beam time at the ISA synchrotron at Aarhus University, Denmark, supported by the European Union (EU) I3 programme ELISA, grant agreement No. 226716. We also acknowledge the financial support provided by the European Commission through the Access to Research Infrastructure action of the Improving Human Potential Programme. A part of research described in this paper was performed at the Canadian Light Source, which is supported by the Canadian Foundation for Innovation, Natural Sciences and Engineering Research Council of Canada, the University of Saskatchewan, the Government of Saskatchewan, Western Economic Diversification Canada, the National Research Council Canada, and the Canadian Institutes of Health Research. DD acknowledges the support of the OVERSEE and CAPPA grants, managed by the Agence Nationale de la Recherche under the frame programs Investissements d'Avenir ANR-10-LABX-005 and I-SITE ULNE/ANR-16-IDEX-0004 ULNE, respectively. D.D. also thanks the Région Hauts de France, the Ministère de l'Enseignement Supérieur et de la Recherche (CPER Climibio) and the European Fund for Regional Economic Development for their support. This work used HPC resources from GENCITGCC (grant No. 2019-A0010806820) and the Centre de Ressources Informatiques (CRI) of the Université de Lille. PLV acknowledges the Portuguese National Funding Agency FCT through Research grants UIDB/00068/2020 and PTDC/FISAQM/31281/2017.

\section{Author contribution statement}

MAS performed the PA and PES measurements, overall data analysis and wrote the manuscript. DD performed computations and analysis of their outcomes. SVH and NCJ performed PA measurements, whereas LZ and MMD - PES measurements. PLV performed calculations for the photolysis section. NJM provided the samples for both synchrotron runs. All authors commented on the manuscript. All the authors have read and approved the final manuscript.

Publisher's Note The EPJ Publishers remain neutral with regard to jurisdictional claims in published maps and institutional affiliations.

Open Access This is an open access article distributed under the terms of the Creative Commons Attribution License (https://creativecommons.org/licenses/by/4.0/), which permits unrestricted use, distribution, and reproduction in any medium, provided the original work is properly cited.

\section{References}

1. J.H. Kahn, G.B. Nickol, H.A. Conner, J. Agric. Food Chem. 20, 214 (1972)

2. A.D. Webb, Am. J. Enol. Vitic. 2, 148 (1951)

3. I. Medvedev, F.C.D. Lucia, E. Herbst, Astron. Astrophys. 499, 215 (2009)

4. A. Chaskopoulou, S. Nguyen, R.M. Pereira, M.E. Scharf, P.G. Koehler, J. Med. Entomol. 46, 328 (2009)

5. C.-L. Chen, Y.-H. Chung, H.-Y. Lee, Ind. Eng. Chem. Res. 55, 1347 (2016)

6. J.-P. Lange, R. Price, P.M. Ayoub, J. Louis, L. Petrus, L. Clarke, Angew. Chem. Int. Ed. 49, 4479 (2010)

7. P. Ausloos, Can. J. Chem. 36, 383 (1968)

8. Y. Nunes, G. Martins, N.J. Mason, D. Duflot, S.V. Hoffmann, J. Delwiche, M.-J. Hubin-Franskin, P. LimãoVieira, Phys. Chem. Chem. Phys. 12, 15734 (2010)

9. M.A. Śmiałek, M. Łabuda, J. Guthmuller, M. HubinFranskin, J. Delwiche, D. Duflot, N. Mason, S. Vrønning-Hoffmann, N.C. Jones, P. Limao-Vieira, J. Chem. Phys. 141, 104311 (2014) 
10. M.A. Śmiałek, M. Łabuda, J. Guthmuller, S.V. Hoffmann, N.C. Jones, M.A. MacDonald, L. Zuin, N.J. Mason, P. Limão-Vieira, J. Phys. Chem. A 119, 8647 (2015)

11. M.A. Śmiałek, M. Łabuda, J. Guthmuller, M. HubinFranskin, J. Delwiche, S. Hoffmann, N.C. Jones, N. Mason, P. Limao-Vieira, Eur. Phys. J. D 70, 138 (2016)

12. M.A. Śmiałek, M. Łabuda, M. Hubin-Franskin, J. Delwiche, S. Hoffmann, N.C. Jones, N. Mason, P. LimãoVieira, Eur. Phys. J. D 71, 129 (2017)

13. M.A. Śmiałek, J. Guthmuller, M. Macdonald, L. Zuin, J. Delwiche, M. Hubin-Franskin, T. Lesniewski, N. Mason, P. Limão-Vieira, J. Quantum. Spectrosc. Radiat. Transfer 200, 206 (2017)

14. Y.F. Hu, L. Zuin, G. Wright, R. Igarashi, M. McKibben, T. Wilson, S.Y. Chen, T. Johnson, D. Maxwell, B.W. Yates, Rev. Sci. Instrum. 78, 083109 (2007)

15. T. Reddish, G. Richmond, G. Bagley, J. Wightman, S. Cvejanovic, Rev. Sci. Instrum. 68, 2685 (1997)

16. M.A. Śmiałek, M.A. MacDonald, S. Ptasińska, L. Zuin, N.J. Mason, Eur. Phys. J. D 70, 42 (2016)

17. K. Huber, C. Jungen, J. Chem. Phys. 92, 850 (1990)

18. D. Shaw, D. Holland, M. MacDonald, A. Hopkirk, M. Hayes, S. McSweeney, Chem. Phys. 166, 379 (1992)

19. S. Eden, P. Limão-Vieira, S. Hoffmann, N. Mason, Chem. Phys. 323, 313 (2006)

20. N. Mason, J. Gingell, J. Davies, H. Zhao, I. Walker, M. Siggel, J. Phys. B 29, 3075 (1996)

21. W. Chan, G. Cooper, C. Brion, Phys. Rev. A 44, 186 (1991)

22. D. Duflot, S.V. Hoffmann, N.C. Jones, P. Limão-Vieira, in Radiat. Bioanal. Spectrosc. Tech. Theor. Methods, edited by A.S. Pereira, P. Tavares, P. Limão-Vieira (Springer International Publishing, Cham, 2019) pp. 43-81

23. M.J. Frisch, G.W. Trucks, H.B. Schlegel, G.E. Scuseria, M.A. Robb, J.R. Cheeseman, G. Scalmani, V. Barone, G.A. Petersson, H. Nakatsuji, X. Li, M. Caricato, A.V. Marenich, J. Bloino, B.G. Janesko, R. Gomperts, B. Mennucci, H.P. Hratchian, J.V. Ortiz, A.F. Izmaylov, J.L. Sonnenberg, D. Williams-Young, F. Ding, F. Lipparini,
F. Egidi, J. Goings, B. Peng, A. Petrone, T. Henderson, D. Ranasinghe, V.G. Zakrzewski, J. Gao, N. Rega, G. Zheng, W. Liang, M. Hada, M. Ehara, K. Toyota, R. Fukuda, J. Hasegawa, M. Ishida, T. Nakajima, Y. Honda, O. Kitao, H. Nakai, T. Vreven, K. Throssell, J.A. Montgomery Jr., J.E. Peralta, F. Ogliaro, M.J. Bearpark, J.J. Heyd, E.N. Brothers, K.N. Kudin, V.N. Staroverov, T.A. Keith, R. Kobayashi, J. Normand, K. Raghavachari, A.P. Rendell, J.C. Burant, S.S. Iyengar, J. Tomasi, M. Cossi, J.M. Millam, M. Klene, C. Adamo, R. Cammi, J.W. Ochterski, R.L. Martin, K. Morokuma, O. Farkas, J.B. Foresman, D.J. Fox, Gaussian 16 Rev. B.01 (Wallingford, CT, 2016)

24. H.V.L. Nguyen, Private communication

25. A.O. Hernandez-Castillo, C. Abeysekera, B.M. Hays, I. Kleiner, H.V.L. Nguyen, T.S. Zwier, J. Mol. Spectrosc. 337, 51 (2017)

26. Y. Zhao, D.G. Truhlar, Theor. Chem. Acc. 120, 215 (2008)

27. T.H. Dunning, J. Chem. Phys. 90, 1007 (1993)

28. D.E. Woon, T.H. Dunning, J. Chem. Phys. 98, 1358 (1993)

29. K. Kaufmann, W. Baumeister, M. Jungen, J. Phys. B 22, 2223 (1989)

30. R.L. Martin, J. Chem. Phys. 118, 4775 (2003)

31. Chemcraft - graphical software for visualization of quantum chemistry computations, https: //www. chemcraftprog.com

32. H.H. Corzo, A. Galano, O. Dolgounitcheva, V.G. Zakrzewski, J.V. Ortiz, J. Phys. Chem. A 119, 8813 (2015)

33. H.H. Corzo, J.V. Ortiz, in Adv. Quantum Chem., edited by J.R. Sabin, E.J. Brändas (Academic Press, 2017) pp. 267-298

34. W.B. DeMore, S.P. Sander, D.M. Golden, R.F. Hampson, M.J. Kurylo, C.J. Howard, A.R. Ravishankara, C.E. Kolb, M.J. Molina, Evaluation Number 12, January 15, JPL Publication 97-4, 1997

35. P. Limão-Vieira, S. Eden, P. Kendall, N. Mason, S.V. Hoffmann, Chem. Phys. Lett. 364, 535 (2002)

36. S. LeCalve, G. LeBras, A. Mellouki, J. Phys. Chem. A 101, 9137 (1997) 